\title{
Relationship between Academic Procrastination and Attributions of Achievement Motivation
}

\author{
Luis Enrique Quispe-Bendezú, Rey Luis Araujo-Castillo, \\ José Enrique García-Tejada, Yuri García-Tejada \\ Universidad Nacional de San Agustín de Arequipa, Perú \\ Antonio Silva Sprock \\ Universidad Central de Venezuela \\ Klinge Orlando Villalba-Condori \\ Universidad Continental, Arequipa, Perú
}

\begin{abstract}
The research aims to determine the relationship between the tendency to academic procrastination and the motivational attributions of achievement in students of the seventh cycle of the EBR of the province of Arequipa. The research is divided into two, first the adaptation and validation of the General Achievement Attribution Motivation Scale (EAML-G) of Durán-Aponte and Pujol (2013) to a secondary level student population, for this, the data are collected from a sample of 72 students, of which 35 were women and 37 men between 15 and 17 years old; the items for the new population were modified; The results show that the adapted General Achievement Motivation Scale (EAML-G) is valid and reliable to identify the causal attributions of general performance in secondary level students. The second research was focused on determining the relationship itself, for this the analysis was made in a representative sample of 677 students, aged between 14 and 19 years, with an average of 15.78 years, of which 476 were male and 201 women, it was found that procrastination is inversely related to the attributions to the interest, capacity, characteristics of the task and teacher evaluation, likewise, the relationship between Academic Procrastination and age is fragile.
\end{abstract}

Keywords: Academic Procrastination; Attribution of Achievement Motivation; Sociodemo-graphic variable

\section{Introduction}

Procrastination is a phenomenon that affects people, not recently, as there is evidence that the consequences of procrastination have been known since, even before Christ, but that it has recently begun to be studied with significant momentum and dedication, since this phenomenon causes in the subject, a voluntary delay of the tasks, of any type, to do other trivial activities without 
any objective, this is harmful to the mental health of the individuals because it brings with it stress and the feeling of guilt for not doing things in time. This in an academic field is better known, since all students go through a similar situation. In the case of teenagers, it is a very recognizable phenomenon.

Various studies emphasize the discomfort it causes and the negative consequences it brings, as well as the negative factors associated with procrastination.

The research conducted by Hen and Goroshit (2018) aimed to examine the effects of academic and decisional procrastination on student discomfort related to academic procrastination and the desire to change their procrastination habits, in a total of 373 university students of social sciences in northern Israel. The result was that procrastination is associated with feelings of discomfort. However, academic procrastinators, have desires to change their procrastinating habits, but do not feel uncomfortable having them, this supports the idea that procrastination can serve as immediate emotional relief, even though it is immediately followed by negative academic results, which causes these students to change their practices.

Constantin, English and Mazmanian (2018) sought to clarify the role of repetitive negative thinking (i.e., rumination and worry) in links between anxiety and procrastination, and depression and procrastination in a sample of 90 undergraduate students. After the research was carried out it was found that procrastination correlates directly with the other variables, more significantly with rumination, concluding, then, that students with higher levels of anxiety and depression participate in more negative repetitive thinking, which may contribute to procrastinating behavior as a result of a concern for depressing or painful thoughts about the past.

Goroshit, Hen and Ferrari (2018) found in their research that there are strong associations between repentance regarding procrastination and that the Repentance of vital dominance about to procrastination is multidimensional and that is why cultural differences can be found.

Wang et al. (2019) determined the predictive role of sensation seeking in smartphone addiction in adolescents was examined and also investigated whether the fear of getting lost (FoMO) and procrastination sequentially mediated the relationship between sensation seeking and smartphone addiction in adolescents, in a sample of 794 adolescents, finding that the partial procrastination partially and sequentially the relationship between the search for feelings and addiction to smartphones in teenagers.

Similarly, procrastination is investigated with goals and objectives, indirect relationships that are discovered with research in various samples.

Chen (2017) in his research seeked to examine the relationship between academic procrastination and bedtime and the indirect and moderating effects of 
Sensation search and disconnection of objectives in that relationship in one hundred ninety-nine undergraduate chinese students (Average $=19.3$ years) . The research found that the relationship is stronger for those students with higher levels of goal disconnection than for those students with lower levels of goal disconnection.

The research prepared by Liu and Feng (2019) proved that the perspective of future time is significantly correlated with procrastination.

Focusing more information on what merits research, procrastination is also associated with the locus of control, that is, the belief that power to change or influence something is internally or externally of each one.

Zarzycka, Liszewski and Marzel (2019), in their research sought to examine the relationship between religiosity and procrastination, with the locus of control and prayer styles playing mediation roles in 196 students, determining at the end of their investigation that religious people can give up internal control, believing that their affairs are in the hands of God. Being subject to the power of God provides them with a form of replacement control, which reduces the problems of self-regulation.

Other research, developed by Kurtovic, Vrdoljak and Idzanovic (2019) aimed to examine the relationships of academic achievement, self-efficacy and perfectionism with procrastination in university students, using a sample of 277 university students, demonstrating that there are negative correlations between academic performance, self-efficacy and adaptive perfectionism with procrastination, and a positive relationship between maladaptive perfectionism and procrastination.

Also, Vicent et al. (2019) seeks to identify the relationship between child perfectionism and causal academic self-attributions using a dual approach: variable-oriented and oriented to the person in a sample of 431 spanish students $(49.42 \%$ girls) between the ages of eight and 11, the results indicate that nonperfectionism scores tend to involve their learning to external causes and not so much to lack of effort.

Conceming sociodemographic variables, and there is no consensus, as several investigations find some significant with age and sex, but others do not find such a relationship.

Otherwise, Zhou (2018) examined active and passive procrastination to identify personality traits that affect procrastination and to compare and contrast this relationship between men and women. In this investigation it was found that personality traits play different roles in these two forms of procrastination in different gender groups.

Dominguez, Prada and Moreta (2019) in their research seek to determine the existence of differences between men and women regarding the influence of the 
dimensions of personality on academic procrastination in 986 students between 16 and 40 years of undergraduate of two universities in Lima, determines that character explains a significant percentage of the variability of the dimensions of academic procrastination, and that the influence of the dimensions of responsibility and Neuroticism was higher in women.

In the research by Ferrari and Roster (2018) was explored how two types of procrastination (indecision and behavior) contribute to disorder problems in three adult US samples. UU, the three adult samples are made up of three groups, whose average age is 21, 31 and 54 years, finding that general procrastination trends can allow a pattern of lifelong responses to the environment that becomes increasingly misfit throughout the life cycle, which simultaneously delays elimination decisions.

In the research conducted by Díaz (2018) provide an overview of the research conducted on procrastination in the spanish population organized in the following sections: conceptual framework of procrastination, instruments of measurement, prevalence and differences according to age, sex and occupation, structural models, types of procrastination and correlates (personality styles, temporal perspective, maturity, and mortality). They not concluded nothing about gender and age, because is no consensus in the research.

It is therefore worthwhile to make an intervention with the students who procrastinate in their studies. In the face of this problem, research has also been done to determine the most effective ways to approach the phenomenon.

In the research by Celik and Odac1 (2017), they analized effectiveness of a psychoeducational group intervention based on reality therapy to treat young people with academic procrastination, in university students of a state university in the eastern Black Sea region in Turkey. It was 10 sessions and affected the decrease of academic postponement behavior of university students.

Sirois, Nauts and Molnar (2019) in their research sought to expand previous research on self-pity and health behaviors by examining associations of self-pity with procrastination before bedtime. This was done in 2 studies, the first with 134 individuals and the second with 646, finding at the end of the investigation that self-compassionate people are less likely to participate in the postponement of bedtime, due in part to the use of healthy strategies of emotional regulation that negatively regulate the negative mood.

In the research conducted by Zhao et al. (2019), it was sought to determine the influence and mechanism of the management disposition of time and selfcontrol about procrastination in a sample of 503 Chinese university students. They finding that procrastination is negatively correlated with the distribution of time management and restraint, while self-control moderated the effect of management disposition of time on procrastination. The research concluded that restraint is a variable of capital importance in the research of procrastination and time management. 
Katz, Eilot and Nevo (2014) in their research explored the role of motivation in the relationships between self-efficacy and procrastination in 171 Fifth grade students. Their results indicate that the average autonomous motivation and moderates the relationships between self-efficacy and procrastination, this suggests that procrastination is not reduced by directly addressing self-efficacy. Also they should be supported so that they find a more autonomous type of motivation.

In the research prepared by Goroshit and Hen (2019), the relationship between academic procrastination and academic performance, and the moderating role of learning disabilities in this relationship, concluding that a high level of procrastination could be more detrimental to the academic performance of these students.

The research conducted by Balkis and Duru (2019) focuses on the integrated effect of doubt, rational and irrational beliefs and fear of failure in procrastination in a sample of Turkish undergraduate students $(\mathrm{N}=293)$. They determined that doubt, fear of failure and rational/irrational beliefs were essential predictors of procrastination and secondly, doubt as Irrational expectations have direct and interactive effects on fear of failure, concluding then that intervention attempts should focus on modifying irrational beliefs and improving rational beliefs to deal with procrastination.

Cerezo et al. (2018) analyzed how training in self-regulated learning strategies is related to improvements in the knowledge of those strategies, the self-efficacy in the use of these strategies, their perceived usefulness and their effective use in academic learning tasks. For this purpose they used a control group made up of 206 university students and an experimental group made up of 167. They determined that the training in said strategies produced a statistically significant improvement in the knowledge of self-regulated learning strategies, which was associated with a significant increase in self-efficacy in the use of those strategies.

\subsection{Academic procrastination}

Procrastination is a phenomenon present in several aspects of human life, one of them is in the academic field, this type of procrastination is understood as "an unnecessary and unjustified delay of the tasks related to studies" (Rodríguez \& Clariana, 2016). Academic procrastination is maintained in the subject because they prefer to do other more pleasant activities that will cause more momentary satisfaction (Tarazona, et. al., 2016).

Summarizing the above, it can be affirmed that academic procrastination (PA) is the act of dilating time before starting an educational activity, voluntarily, but that brings subjective unrest. This delay may be due to external factors such as the difficulty of the task or internal factors such as the lack of pleasure that it has for the procrastinating subject (Dominguez, Villegas \& Centeno, 2014). That is, in 
the personal affectation of procrastination there is still much to research to have a homogeneous idea of what produces academic procrastination in students.

For the PA to be understood in a more structural way, it is necessary to know that this phenomenon has two distinct components, the first is the core of the procrastination itself, the delay of activities, the second does instead, reference to self-regulation, because there are no behaviors that are oriented towards the goals of the procrastinators. There is no capacity to plan those (Steel, 2007).

In this sense, we can find two types of scholarly procrastinators, the sporadic, which refers to some punctual behavior in which some academic activity is delayed in some specific situation and the chronic procrastinator, which is a habit of procrastinating in the educational field (Schouwenburg, 2004).

Besides another classification was proposed, that of the passive procrastinator, which is the one that delays the academic activities, which expands the time before starting the task and that this is due to a functional and active mismatch, which in the same way, delays the beginning of the job, but that does so voluntarily, because it prefers to work under pressure (Chun \& Choi, 2005).

\subsection{Attribution of achievement motivation}

People tend to look for the causes of our actions and that way we will try to determine if we will succeed or fail when we insist on solving a problem.

This is reflected very clearly in the cases that take place in school contexts, as students wonder about their failures and their successes, why they obtained a good or bad result, to find an answer they will try many possibilities, among them, internal factors, such as their capacity or effort and external factors, such as teacher or luck, that is the foundation of attribution theory (Gonzales, 1999).

This model aims to determine the dependence between motivation and the causes of the results that have been obtained after carrying out a task (Álvarez, 2012).

This model indicates that the student attributes his successes or failures to internal or external factors, either one or the other, these factors have dimensions, these are, locus, stability, controllable character and attributional patterns (Durán-Aponte \& Pujol, 2013).

\section{Method}

\subsection{Population and Sample}

In this investigation the Proportional Stratified Probabilistic Design was used. For the validation of the General Attribution Motivation Scale of Achievement (EAML-G), 72 students were taken as a sample for the pilot test, of which 35 were women and 37 men between 15 and 17 years researching in fourth and fifth 
High school. To determine the relationship, the population corresponds to fourth and fifth-year high school students in the city of Arequipa, obtaining a representative sample of 677 students, aged between 14 and 19 years, with an average of 15.78 years, of which 476 were men and 201 women. Also, 339 correspond to the fourth grade of secondary school, while 338 to the fifth grade of six conventions, national and private schools in the city.

\subsection{Instruments}

\subsubsection{Academic Procrastination Scale (EPA)}

For the measurement of the tendency towards procrastination, the Academic Procrastination Scale (EPA) was used, consisting of 16 closed items that are answered on a Likert scale ranging from 1 (Always) to 5 (Never). Specifically, the adapted version of Álvarez (2010) was used. This adaptation has 16 closed items, "the items are statistically significant, with an internal consistency coefficient Cronbach's alpha that amounts to 0.80, which allows concluding that the EPA presents reliability. The measure of adequacy of the Kaiser-Meyer-Olkin sampling reaches a value of 0.80 , which indicates that the variables have an adequate explanatory potential. Bartlett's sphericity test reaches a value that is significant (Chi-square $=701.95 \mathrm{p}<.05)$, which indicates that the correlations between the items of the instrument are high enough to continue with the factor analysis" (Álvarez, 2010).

The scale has a one-dimensional structure, that is, a single factor that explains $23.89 \%$ of the total variance of the instrument (Dominguez \& Campos, 2017).

\subsubsection{Attribution of Motivation to General Achievement Scale (EAML-G)}

It was developed by Manassero and Vásquez (1998), the original scale consists of 22 items that are answered on a Likert scale ranging from 1 to 6, but for the research the adaptation of Durán-Aponte and Pujol (2013) was taken. It assesses the expectations of success and failure of a student in their overall performance, has a "KMO index (.864) which is close to the unit. Therefore indicates excellent adequacy of the data to a factorial analysis model. Bartlett's contrast, meanwhile, showed a p-value of 0.00 which means the existence of a significant correlation between the variables. In the initial solution, the varimax rotation method reaches convergence after eight iterations, resulting in a factorial structure that explains $47.34 \%$ of the total variance and allows four factors to be extracted" (Durán-Aponte \& Pujol, 2013). It was determined that the scale has the appropriate psychometric properties for its application.

\subsubsection{Data collection and analysis procedure}

Authorization was requested from the authors of the adaptation of the EAML-G size to adapt it to the secondary school student population. The help of two psychologists and a secondary level teacher was also requested to modify the wording of the items and subsequently the new scale was applied in a pilot test, the appropriate psychometric properties for the investigation was determined. 
Some educational institutions that provide education at the secondary level of the city of Arequipa were chosen, to which an interview with the Director was requested to deliver the letter of presentation of the Faculty of Education Sciences of the UNSA, explain the purpose of the investigation and request access to the classrooms to apply the levels. Once our request was accepted, the schedules for the application of the scales in the school were coordinated with the prior consent of the teachers and the students. Subsequently we proceeded to the qualification, analysis and interpretation of the data obtained.

The data are presented in the form of tables and for the processing of the information and the statistical program SPSS in its version 23.0 was used.

\section{Results}

The EAML-G instrument was reviewed and modified with the help of two educational psychologists and a secondary level teacher. They made some observations in the writing of some reagents, once corrected no difficulties were found for the application in the required sample.

The construct validity of the adaptation of the EAML-G was analyzed by analyzing the factor structure using the principal component analysis. For this the Kaiser-Meyer-Olkin index (KMO) was obtained, obtaining a result of 0.771 , being close to the unit indicates an adequacy of the data to a factor analysis model; Bartlett's contrast showed a p-value of 0.00 which means that there is a significant correlation between the variables, these results are shown in Table 1.

However, the Anti-Image Correlation indicated that one of the items should be eliminated because it had the lowest correlation, in the same way the table of commonalities recommended the elimination of another of the details. After all, it had an extraction value less than 0.4 , of which so that the scale was no longer with 18 , but with 16 questions.

Therefore, the Kaiser-Meyer-Olkin (KMO) index was obtained again, obtaining a result of 0.816 , which, being close to the unit, indicates an excellent adaptation of the data to a factorial analysis model. Bartlett's contrast showed a p-value of 0.00 which means that there is a significant correlation between the variables, these results are shown in Table 2 .

Table 1: Kaiser Meyer Olkin's test of the original EAML-G

\begin{tabular}{|l|l|r|}
\hline \multicolumn{2}{|c|}{ KMO and Bartlett test } \\
\hline Kaiser-Meyer-Olkin measurement of sampling adequacy &, 771 \\
\hline Bartlett's sphericity test & Chi-square approach & 577,032 \\
\cline { 2 - 3 } & Gl & 153 \\
\cline { 2 - 3 } & Sig. &, 000 \\
\hline
\end{tabular}


Table 2: Kaiser Meyer Olkin test of the adapted EAML-G

\begin{tabular}{|l|c|c|}
\hline \multicolumn{3}{|c|}{ KMO and Bartlett test } \\
\hline Kaiser-Meyer-Olkin measurement of sampling adequacy &, 816 \\
\hline Bartlett's sphericity test & Chi-square approach & 510,758 \\
\cline { 2 - 3 } & gl & 120 \\
\cline { 2 - 3 } & Sig. &, 000 \\
\hline
\end{tabular}

In this new version, the varimax rotation method was used that reaches convergence after seven interactions, resulting in a factorial structure that explains $65.37 \%$ of the total variance and allows four factors to be extracted.

With this new version they were grouped into four components that can be seen in Table 3, for this the Anti-image Correlation and the table of commonality were verified, determining that all the values are adequate, the new classification is separate from that of the instrument of Durán-Aponte and Pujol (2013).

One of the deleted items is "How fair are your notes from the previous twomonth period about what you deserved?" For having the lowest value (0.283), said reagent was part of the "Attribution to teacher evaluation" factor of the original scale of Durán-Aponte and Pujol (2013), it refers to all the curricular areas of the previous two-month period. In the adaptation the same is sought. Still, it is not applicable to all curricular areas because in some you can have a better recognition of truth and in others not, that is to say that the appreciation of justice varies according to the courses, which prevents the assessment of the whole set of curricular areas of a bimester.

The other item deleted is "How do you describe your persistence because you have not been able to do a task this two-month period?" which only obtained a score of 0.357 , for that reason, that item must be deleted. Said reagent belongs to the Durán-Aponte and Pujol (2013) original scale to the "Attribution to the characteristic of the task" factor, its low factor load can be explained as the scale values the attribution to a set of curricular areas and the tasks between these can vary, in some they strive to complete the job and in others they leave quickly. The minimum value is .357 and the maximum is .790 .

Table 3. Rotated component matrix of the modified version of the adapted EML-G

\begin{tabular}{|c|c|c|c|c|}
\hline \multirow{2}{*}{ Item } & \multicolumn{4}{|c|}{ Components } \\
\hline & 1 & 2 & 3 & 4 \\
\hline 9 &, 778 & & & \\
\hline 12 & 761 & & & \\
\hline 16 &, 755 & & & \\
\hline 8 &, 711 & & & \\
\hline 4 &, 599 & & & \\
\hline 6 & &, 883 & & \\
\hline 17 & &, 672 & & \\
\hline
\end{tabular}




\begin{tabular}{|c|l|l|l|l|}
\hline 5 & &, 671 & & \\
\hline 7 & &, 564 & & \\
\hline 15 & &, 504 & & \\
\hline 18 & & &, 820 & \\
\hline 11 & & &, 699 & \\
\hline 14 & & &, 608 & \\
\hline 1 & & &, 511 & \\
\hline 2 & & & &, 826 \\
\hline 10 & & & &, 544 \\
\hline
\end{tabular}

From the resulting factor structure the reliability of the adapted EAML-G is calculated, this with the internal consistency index Alpha of Cronbach, gave a value of, 890 for the instrument in general, in such a way it is determined that the device is reliable. In the same way the internal consistency of each factor was calculated, proving to be satisfactory in all cases, for Factor I the coefficient of, 846 was obtained, for Factor II it was, 822, for Factor II it was, 706 and finally for Factor IV it was 616, as shown in Table 4.

Table 4. Cronbach's alpha for the total scale and the factors of the instrument

\begin{tabular}{|c|c|}
\hline \multicolumn{2}{|c|}{$\begin{array}{l}\text { Cronbach's Alpha for the Allocational Motivation Scale for General } \\
\text { Achievement Adapted }\end{array}$} \\
\hline Total scale & ,890 \\
\hline Factor I & 846 \\
\hline Factor II & 822 \\
\hline Factor III & ,706 \\
\hline Factor IV & 616 \\
\hline
\end{tabular}

In this way the instrument is constituted by 16 reagents, the total difference explained indicates that the reagents are grouped into four factors, the factor structure explains $65.37 \%$ of the total difference with 16 reagents; where factor I explains $39.24 \%$ of the difference, factor II explains $10.20 \%$ of the difference, factor III explains $8.56 \%$ of the difference and factor IV explains $7.37 \%$ of the difference.

It is then as shown in Table 5, likewise also shows the commonalities of the 16 resulting reagents, with a minimum of, 543 and a maximum of, 801 .

Table 5. Factorial Structure of the adapted EAML-G

\begin{tabular}{|l|c|l|}
\hline Factors & Commonalities & \multicolumn{1}{c|}{ Items } \\
\hline \multirow{4}{*}{ Factor I } &, 663 & $\begin{array}{l}\text { How much interest do you have in researching this } \\
\text { bimester? }\end{array}$ \\
\cline { 2 - 3 } &, 709 & How much interest do you have to get good grades? \\
\cline { 2 - 3 } &, 613 & How much desire do you have to learn this bimester? \\
\hline \multirow{2}{*}{, 746} & $\begin{array}{l}\text { How important are good grades for you in this two-month } \\
\text { period? }\end{array}$ \\
\hline
\end{tabular}




\begin{tabular}{|c|c|c|}
\hline &, 586 & $\begin{array}{l}\text { How much effort are you currently making to get good } \\
\text { grades in this two-month period? }\end{array}$ \\
\hline \multirow{5}{*}{ Factor II } & 801 & $\begin{array}{l}\text { How much chance of passing the curricular areas do you } \\
\text { think you have this bimester? }\end{array}$ \\
\hline & 603 & How often do you complete a task you have started? \\
\hline & 689 & $\begin{array}{l}\text { How much confidence do you have to pass all curricular } \\
\text { areas in this bimester? }\end{array}$ \\
\hline & ,681 & $\begin{array}{l}\text { How do you value your ability to research curricular } \\
\text { areas? }\end{array}$ \\
\hline & 625 & $\begin{array}{l}\text { How do you describe your behavior when you make a } \\
\text { severe problem in any of your curricular areas? }\end{array}$ \\
\hline \multirow{4}{*}{$\begin{array}{c}\text { Factor } \\
\text { III }\end{array}$} & 694 & $\begin{array}{l}\text { How often do you get bored in the classes of the curricular } \\
\text { areas of this bimester? }\end{array}$ \\
\hline &, 585 & $\begin{array}{l}\text { To what degree do evaluations influence the increase or } \\
\text { decrease of the grades you deserve this two-month period? }\end{array}$ \\
\hline &, 571 & $\begin{array}{l}\text { How do you rate the demands that you impose on } \\
\text { yourself in the research? }\end{array}$ \\
\hline &, 543 & $\begin{array}{l}\text { What is the degree of satisfaction you have about your } \\
\text { previous two-month grades? }\end{array}$ \\
\hline \multirow{2}{*}{$\begin{array}{c}\text { Factor } \\
\text { IV }\end{array}$} & ,735 & $\begin{array}{l}\text { How do you assess the relationship between the grade you } \\
\text { obtained from the previous aimentre and the degree you } \\
\text { expected to get? }\end{array}$ \\
\hline & ,618 & $\begin{array}{l}\text { How much satisfaction does it give you to research the } \\
\text { curricular areas of this bimester? }\end{array}$ \\
\hline
\end{tabular}

From the analysis of the instrument four scales arise, as is the case of DuránAponte and Pujol (2013). However the distribution of the items is different, since two reagents were eliminated and the delivery of the remaining 16 items changed factor. This is understandable, since in this investigation it was adapted in a different sample to the original. For this reason the four factors of the original scale are maintained. However, some items were changed factor, the four elements make the same reference as in the initial investigation; being these the Attribution to the characteristic of the task, the Attribution to the Effort, the Attribution to the Capacity and the Attribution to the evaluation of the professors.

To support the construct validity of the Adapted EAML-G, a correlational analysis was carried out between the four resulting dimensions, as seen in Table 6. In terms of Attribution to interest/effort and Attribution to capacity, there is a relationship moderate positive (.549). This correlation is significant $(p<, .001)$. This means that the more academic achievements are attributed to interest and effort, the more they are also attributed, those achievements, to the ability of the same student. The same happens with the Attribution to interest/effort and the attribution to the characteristic of the task, since the correlation is also positive and moderate (.465) and significant $(\mathrm{p}<, .001)$, that is, the more it is attributed academic achievements to interest and effort, but is also attributed these achievements to the characteristics of the task. 
The result is similar with regard to the Attribution to the capacity and the Attribution to the characteristic of the task, the relationship between both factors is positive and moderate $(, 455)$ and significant $(p<, .001)$, which indicates that while the more academic achievements are attributed to the ability, the more these attributes are also attributed to the characteristics of the task; About the relationship between the Attribution to capacity factor and the Attribution to Teacher evaluation factor, there is a weak $(, 240)$ and significant $(\mathrm{p}<, 05)$ positive relationship, which indicates that although the more the achievements are attributed Academic ability, more is also attributed, such achievements, teacher evaluation, there are other variables involved.

Finally, the relationship between the Attribution to the characteristic of the task factor and the Attribution to the Teacher evaluation factor is positive moderate $(, 404)$ and significant $(p<, 001)$. This is because both factors are variables external to the student, over which he has no control, this means that the more academic achievements are attributed to the characteristics of the task, the more these attributes are also attributed to teacher evaluation.

Table 6. Proof of correlations between factors

\begin{tabular}{|c|c|c|c|c|}
\hline \multicolumn{5}{|c|}{ Correlations } \\
\hline & $\begin{array}{c}\text { Attribution } \\
\text { to interest / } \\
\text { Effort }\end{array}$ & $\begin{array}{c}\text { Attribution } \\
\text { to capacity }\end{array}$ & $\begin{array}{c}\text { Attribution } \\
\text { to the } \\
\text { characteristic } \\
\text { of the task }\end{array}$ & $\begin{array}{c}\text { Attribution } \\
\text { to teacher } \\
\text { evaluation }\end{array}$ \\
\hline $\begin{array}{c}\text { Attribution to } \\
\text { interest / Effort }\end{array}$ & 1,000 &, $549^{* *}$ &, $465^{* *}$ &, 227 \\
\hline $\begin{array}{c}\text { Attribution to } \\
\text { capacity }\end{array}$ & 1,000 &, $455^{* *}$ &, $240^{*}$ \\
\hline $\begin{array}{c}\text { Attribution to } \\
\text { the } \\
\text { characteristic of } \\
\text { the task }\end{array}$ & & 1,000 &, $404^{* *}$ \\
\hline $\begin{array}{c}\text { Attribution to } \\
\text { teacher } \\
\text { evaluation }\end{array}$ & & & & 1,000 \\
\hline
\end{tabular}

**. The correlation is significant at the 0.01 level ( 2 tails).

*. The correlation is significant at the 0.05 level (2 tails).

Based on the analysis, it is concluded that the adapted instrument is valid and reliable, which is why the correlations that exist in the variables studied were continued, because the variables did not have a normal distribution, it was used for the analysis Spearman's statistic, showing the results shown in Table 7. Regarding the relationship between the tendency to academic procrastination and Attribution to interest/Effort shows that the correlation coefficient indicates that the value of Sperman's Rho is - .522, which establishes a moderate negative correlation, which means that both variables have a moderate and inverse 
correlation, that is, the more success or failure is attributed to interest or effort, the less tendency to procrastination exists.

However, because the correlation is only moderate, there are other variables that influence the trend towards academic procrastination. On the other hand, the $\mathrm{p}$ value is .000 which indicates that the correlation is significant, since it does not exceed .05 .

On the other hand, regarding the relationship between the tendency to academic procrastination and Attribution to capacity, the correlation coefficient indicates that the value of Sperman's Rho is -.457 , which establishes a moderate negative correlation, which means that both variables have a reasonable and inverse relationship, that is, the more success or failure is attributed to the capacity, the less tendency to procrastination exists.

However because the correlation is only modest, there are other variables that influence in the tendency to academic procrastination. On the other hand, the pvalue is .000 which indicates that the relationship is significant, since it does not exceed .05 .

Similarly, the correlation between the tendency to academic procrastination and attribution to the characteristic of the task was analyzed, the correlation coefficient indicates that the value of Sperman's Rho is -.528, which establishes a moderate negative correlation, which indicates that both variables have a moderate and inverse correlation, that is, the more success or failure is attributed to the characteristic of the task, the less tendency to procrastination exists. However, because the correlation is only moderate, there are other variables that influence the propensity to academic procrastination. On the other hand, the $\mathrm{p}$ value is .000 which indicates that the correlation is significant, since it does not exceed 05 .

Regarding the relationship between the tendency to academic procrastination and Attribution to the evaluation of the Teacher, the correlation coefficient indicates that the value of Sperman's Rho is -.262, which establishes a weak negative correlation, meaning that both variables have a soft and inverse correlation. That is to say, the more the success or failure is attributed to the evaluation of the Teacher, the less tendency to procrastination exists. However, because the correlation is weak, there are other variables that influence the propensity to academic procrastination. On the other hand, the p-value is .000 which means that the correlation is significant, since it does not exceed 05 .

Finally, between the trend towards academic procrastination and Age, the correlation coefficient indicates that the value of Sperman's Rho is .155, which establishes a very weak positive correlation, indicating that both variables have a very weak relationship and direct, that is, the older the person evaluated, the more procrastination tendency exists. However because the correlation is very weak, there are other variables that influence the propensity to academic 
procrastination. On the other hand, the p-value is .000 which indicates that the correlation is significant, since it does not exceed 05 .

Table 7. Correlations between EPA and attributions and age

\begin{tabular}{|l|l|c|c|c|c|c|}
\hline & \multicolumn{6}{|c|}{ Correlations by Rho de Spearman } \\
\hline & Variables & $\begin{array}{c}\text { Attribution } \\
\text { to interest / } \\
\text { Effort }\end{array}$ & $\begin{array}{c}\text { Attribution } \\
\text { to capacity }\end{array}$ & $\begin{array}{c}\text { Attribution } \\
\text { to the } \\
\text { characteristic } \\
\text { of the task }\end{array}$ & $\begin{array}{c}\text { Attribution } \\
\text { to teacher } \\
\text { evaluation }\end{array}$ & Age \\
\hline \multirow{2}{*}{ EPA } & $\begin{array}{l}\text { Spearman's } \\
\text { Rho }\end{array}$ &,- 522 &,- 457 &,- 528 &,- 262 &, 155 \\
\cline { 2 - 8 } & Sig. &, 000 &, 000 &, 000 &, 000 &, 000 \\
\hline
\end{tabular}

Regarding the correlation between the tendency to academic procrastination and sex, the Mann Whitney $U$ test was used because the sex variable is a categorical variable, as recorded in Table 8 since the p-value is .678. It is concluded that, although there are differences, these are not significant, that is, there is no correlation between the age of the students and the tendency towards academic Procrastination.

Table 8: Correlation between EPA and Sex

\begin{tabular}{|l|c|}
\hline \multicolumn{2}{|c|}{ Test Statistics } \\
\hline & $\begin{array}{c}\text { Academic Procrastination } \\
\text { Level }\end{array}$ \\
\hline U from Mann-Whitney & 46942,000 \\
\hline Wilcoxon W & 67243,000 \\
\hline$Z$ &,- 416 \\
\hline $\begin{array}{l}\text { Sig. asymptotic } \\
\text { (bilateral) }\end{array}$ &, 678 \\
\hline a. Grouping variable: Sex & \\
\hline
\end{tabular}

\section{Discussion and Conclusions}

There is an inverse relationship between the tendency to academic procrastination and the motivational attributions of achievement in students of the seventh cycle of the EBR of the province of Arequipa. This correlation is 0.595, which is equivalent to a moderate level. Likewise established a Simple Linear Regression model. There is also a direct relationship between the procrastination and the age of the students, but it is 0.155 , which indicates that it is fragile and there is no significant correlation between the levels of procrastination and the sex of those evaluated.

Considering the research in 6 national, private and agreement schools of the city of Arequipa, it is determined that 179 students obtained scores that are located under the first quartile, considering them at a low level of academic 
procrastination, 317, between the first and third quartile, placing them at a medium level of educational procrastination trend and 181 obtained scores that are above the third quartile, which puts them at a high level of aducational procrastination trend.

Specifically, the results were 188, 323 and 166 students located in the low, medium and high levels, respectively, in terms of attribution to academic achievements of interest or effort. 173, 310 and 194 students are found in the low, medium and high levels, respectively, in terms of attribution to academic performance; 199, 316 and 162 are located in the low, medium and high levels respectively in terms of attribution to the characteristics of the task, their academic achievements and 218, 282 and 177 students are located in the low, medium and high levels respectively in the attribution to the evaluation of the teacher of his academic achievements. The levels were located according to the score obtained by the students evaluated.

The results are consistent with those found by Durán \& Pujol (2013) the validated scale has the necessary validity to be applied to the population in which it was adapted with statistical values similar to those found by the aforementioned authors.

The results obtained, finally, are verified with those that Howell and Watson (2007) affirm, within the personal characteristics that favor the postponement of tasks are those linked with a low motivation to the achievement, declaring that both variables are negatively related. This is reinforced by García and Silvia (2019), where they indicate the same, that procrastination is associated with low levels of motivation for achievement. Also to them, Wolters, Pintrich, and Karabenick (2003) affirm that academic procrastination is linked to the use of motivational regulation, this, emphasizing academic procrastination. Along the same lines, Matalinares Calvet et al.. (2017) indicates that procrastination is related to low motivation. This is ratified with Steel (2007) when it states that procrastinating behavior is linked to the degree of active commitment to a specific task, this within a motivational process.

About the differences of the relationships between internal and external factors with procrastination, since in the investigation, the "teacher evaluation" factor obtained a weaker connection it is ratified by what Klassen, Krawchuk, Lldynch, \& Rajani point out (2007), because they suggest that procrastination is explained less and to a lesser extent by intrinsic motivational variables. This is also found by Lee (2005) who indicates that students who are moved more for internal reasons than for external ones are less likely to procrastinate.

Regarding the relationship between age and sex and procrastination, studies such as Pardo, Perilla and Salinas (2014) indicate the same thing that was found in the present investigation, that these sociodemographic variables are not predictors of procrastination in the academic field. The same happens in the study of Álvarez (2010) in which the difference that exists between the levels of procrastination by sex or age is not significant. 
Finally Dominguez, Villegas and Centeno (2014) in their research indicate that there are no significant differences about to sex. Similarly Cerniglia (2019) suggests that there are no significant differences between the levels of procrastination between men and women or in terms of the age of both. Diaz (2018) indicates that the gap between gender and age groups they are not predictors and they are not determined concerning procrastination, but this is because the ages that are generally taken are those of university students. These ages do not oscillate much and that restriction demonstrates a real trend.

\section{References}

Álvarez, B. Ó. R. (2010). Procrastinación general y académica en una muestra de estudiantes de secundaria de Lima metropolitan [General and academic procrastination in a sample of secondary students in metropolitan Lima]. Persona: Revista de la Facultad de Psicología, 13, 159-177. http:/ /10.26439/ persona.

Álvarez, R. L. Y. (2012). Escala de motivación adolescente (EM1) basada en el Modelo Motivacional de McClelland [Teen Motivation Scale (EM1) based on the McClelland Motivational Model]. Tesis Psicológica, 7, 128-143.

Balkis, M., \& Duru, E. (2019). Procrastination and Rational/Irrational Beliefs: A Moderated Mediation Model. Journal of Rational-Emotive \& Cognitive-Behavior Therapy, 37, 299-315. https://doi.org/10.1007/s10942-019-00314-6

Cerezo, R., Fernández, E., Amierio, N., Valle, A., Rosário, P., \& Núñez, J. C. (2018). Mediating Role of Self-efficacy and Usefulness Between Self-regulated Learning Strategy Knowledge and its Use. Revista de Psicodidáctica, 24(1) 1-8. http://10.1016/j.psicoe.2018.09.001

Cerniglia , L. (2019). An exploratory research on adaptive psychopathological risk and problematic use of the web associated with procrastination in university students. International Journal of Developmental and Educational Psychology, 1, 4148. https:// doi.org/10.17060/ijodaep.2019.n1.v1.1382

Chen, B. B. (2017). Academic Procrastination and Bedtime among Chinese Undergraduates: The Indirect and Moderating Effects of Sensation Seeking and Goal Disengagement. Current Psychology volume, 38, 187-193. https://doi.org/10.1007/s12144-017-9605-9

Chun, A., \& Choi, J. (2005). Rethinking Procrastination: Positive Effects of "Active" Procrastination Behavior on Attitudes and Performance. The Journal of Social Psychology, 145(3), 245-264. http://10.3200/SOCP.145.3.245-264

Constantin, K., English, M. M., \& Mazmanian, D. (2018). Anxiety, Depression, and Procrastination Among Students: Rumination Plays a Larger Mediating Role than Worry. Journal of Rational-Emotive \& Cognitive-Behavior Therapy, 36, 15-27. https://doi.org/10.1007/s10942-017-0271-5

Çelik, Ç. B., \& Odacı, H. (2017). Psycho-Educational Group Intervention Based on Reality Therapy to Cope with Academic Procrastination. Journal of Rational-Emotive $\mathcal{E}$ Cognitive-Behavior Therapy, 36, 220-233. https://doi.org/10.1007/s10942-0170283-1

Díaz, M., J. F. (2018). Procrastinación: Una Revisión de su Medida y sus Correlatos [Procrastination: A Review of its Measure and its Correlates]. Revista Iberoamericana de Diagnóstico y Evaluación - e Avaliação Psicológica RIDEP, 51, 4360. https:// doi.org10.21865/RIDEP51.2.04

Dominguez, L., S. A., \& Campos, U., Y. (2017). Influencia de la satisfacción con los estudios sobre la procrastinación académica en estudiantes de psicología: un estudio preliminary [Influence of satisfaction with studies on academic 
procrastination in psychology students: a preliminary research]. Liberabit, Revista de Psicología, 23(1), 123-135. https://doi.org/10.24265/liberabit.2017.v23n1.09

Dominguez, L., S. A., Villegas G., G., \& Centeno L., S. B. (2014). Procrastinación académica: Validación de una escala en una muestra de estudiantes de una universidad privada [Academic procrastination: Validation of a scale in a sample of students from a private university]. Liberabit, Revista de Psicología, 20(2), 293-304.

Dominguez, L., S., Prada, C., R., \& Moreta, H., R. (2019). Diferencias de género en la influencia de la personalidad sobre la procrastinación académica en estudiantes universitarios peruanos [Gender differences in the influence of personality on academic procrastination in Peruvian university students]. Acta Colombiana de Psicología, 22(2), 125-136. http://10.14718/ ACP.2019.22.2.7

Durán-Aponte, E., \& Pujol, L. (2013). Escala Atribucional de Motivación de Logro General (EAML-G): Adaptación y análisis de sus propiedades psicométricas [Attribution Scale of General Achievement Motivation (EAML-G): Adaptation and analysis of its psychometric properties]. Estudios Pedagógicos, 39(1), 83-97. http://dx.doi.org/10.4067/S0718-07052013000100005

Ferrari, J. R., \& Roster, C. A. (2018). Delaying Disposing: Examining the Relationship between Procrastination and Clutter across Generations. Current Psychology, 37, 427-431. https:/ / doi.org/10.1007/s12144-017-9679-4

García M., V., \& Silvia, P., M. P. (2019). Procrastinación académica entre estudiantes de cursos en línea. Validación de un cuestionario [Academic procrastination among students of online courses. Validation of a questionnaire]. Apertura, 11(2), 122137. http://dx.doi.org/10.32870/Ap.v11n2.1673

Gonzáles, T., C. (1999). Academic motivation: Its determinants and intervention guidelines. (Second ed.). Navarra: Ediciones Universidad de Navarra. S.A. (EUNSA).

Goroshit, M., \& Hen, M. (2019). Academic procrastination and academic performance: Do learning disabilities matter? Current Psychology, 2019. https:// doi.org/10.1007/s12144-019-00183-3

Goroshit, M., Hen, M., \& Ferrari, J. R. (2018). Life-domain regret regarding procrastination (LDR-P): Scale validation in the United States and Israel. Current Psychology, 2018. https://doi.org/10.1007/s12144-018-9801-2

Hen, M., \& Goroshit, M. (2018). The effects of decisional and academic procrastination on students' feelings toward academic procrastination. Current Psychology, 2018. http://10.1007/s12144-017-9777-3

Howell, A., \& Watson, D. (2007). Procrastination: associations with achievement goal orientation and learning strategies. Personality and Individual Differences, 43(1), 167-178. https://doi.org/10.1016/j.paid.2006.11.017

Katz, I., Eilot, K., \& Nevo, N. (2014). "I'll do it later": Type of motivation, self-efficacy and homework procrastination. Motivation and Emotion, 38, 111-119. http://10.1007/s11031-013-9366-1

Klassen, R., Krawchuk, L., Lldynch, L., \& Rajani, S. (2007). Academic procrastination of un-dergraduates: Low selfefficacy to self-regulate predicts higher levels of procrastination. Contemporary Educational Psychology, 33(4), 915-931. https:// doi.org/10.1016/j.cedpsych.2007.07.001

Kurtovic, A., Vrdoljak, G., \& Idzanovic, A. (2019). Predicting Procrastination: The Role of Academic Achievement, Self-efficacy and Perfectionism. International Journal of Educational Psychology, 8(1), 1-26. http://dx.doi.org/10.17583/ijep.2019.2993

Lee, E. (2005). The relationship of motivation and flow experience to academic procrastination in university students. The Journal of Genetic Psychology, 166(1), 514. http://10.3200/GNTP.166.1.5-15 
Liu, P., \& Feng, T. (2019). The effect of future time perspective on procrastination: the role of parahippocampal gyrus and ventromedial prefrontal cortex. Brain Imaging and Behavior, 13(3), 615-622. http://10.1007/s11682-018-9874-4

Manassero, M. A., \& Vázquez, A. Á. (1998). Validación de una Escala de Motivación de Logro [Validation of an Achievement Motivation Scale]. Psicothema, 10(2), 333351.

Matalinares, C. M. L., Diaz, A. A. G., Rivas, D. L. H., Segundio, D. A.D., Arenas, I. C. A., Raymundo, V. O., Baca, D. Espinoza, J. U., Yaringaño, L., J., \& Fernandez, E. (2017). Procrastinación y adicción a redes sociales en estudiantes universitarios de pre y post grado de Lima [Procrastination and addiction to social networks in pre and post graduate university students in Lima]. Horizonte de la Ciencia, 7(13), 63-81. http://10.26490/uncp.horizonteciencia.2017.13.355

Pardo, B. D., Perilla, B. L., \& Salinas, R. C. (2014). Relación entre procrastinación académica y ansiedad-rasgo en estudiantes de psicología [Relationship between academic procrastination and anxiety-trait in psychology students]. Cuadernos Hispanoamericanos de Psicología, 14(1), 31-44. https:// doi.org/10.18270/chps..v14i1.1343

Rodríguez, A., \& Clariana, M. (2016). Procrastinación en Estudiantes Universitarios: su Relación con la Edad y el Curso Académico [Procrastination in University Students: their Relationship with Age and Academic Course]. Revista Colombiana de Psicología, 26(1), 45-60. http://10.15446/rcp.v26n1.53572

Schouwenburg, H. C. (2004). Procrastination in academic settings: General introduction. In H. C. Schouwenburg, T. A. Lay, \& J. R. Ferrari (Eds.), Counseling the procrastinator in academic settings ( $\mathrm{p} 3-17$ ). Washington: American Psychological Association. https://doi.org/10.1037/10808-001

Sirois, F. M., Nauts, S., \& Molnar, D. S. (2019). Self-Compassion and Bedtime Procrastination: an Emotion Regulation Perspective. Mindfulness, 10, 434-445. https://doi.org/10.1007/s12671-018-0983-3

Steel, P. (2007). The nature of Procrastination: A Meta-analytic and theoretical review of quintessential self-regulatory failure. Psychological Bulletin, 133(1), 65-94. https://doi.org/10.1037/0033-2909.133.1.65

Tarazona, P. F., Romero, A. J. N., Aliaga, C. I. M., \& Veliz, R. M. F. (2016). Procrastinación académica en estudiantes de educación en Lenguas, Literatura y Comunicación: Características, modos y factores [Academic procrastination in students of education in Languages, Literature and Communication: Characteristics, modes and factors]. Horizonte de la Ciencia, 6(10), 185-194. http:/ /10.26490/uncp.horizonteciencia.2016.10.214

Wang, J., Wang, P., Yang, X., Zhang, G., Wang, X., Zhao, F., Zhao, M., \& Lei, L. (2019). Fear of Missing Out and Procrastination as Mediators Between Sensation Seeking and Adolescent Smartphone Addiction. International Journal of Mental Health and Addiction, 17, 1049-1062. https:// doi.org/10.1007/s11469-019-00106-0

Wenger, E. C., \& Snyder, W. M. (2000). Communities of practice: The organizational frontier. Harvard Business Review, 78(1), 139-145.

Wolters, C. A., Pintrich, P. R., \& Karabenick, S. A. (2003). Assessing Academic Self Regulated Learning. In Moore, C.A., Lipman, L.H. (Eds.). What Do Children Need to Flourish? Conceptualizing and Measuring Indicators of Positive Development. Washington DC: Springer.

Zarzycka, B., Liszewski, T., \& Marzel, M. (2019). Religion and behavioral procrastination: Mediating effects of locus of control and content of prayer. Current Psychology (2019). https:// doi.org/10.1007/s12144-019-00251-8

Zhou, M. (2018). Gender differences in procrastination: The role of personality traits. Current Psychology (2018). https:// doi.org/10.1007/s12144-018-9851-5 